\title{
Rethinking with the reader
}

\section{BEYOND LAW}

The "law-language" theme is more complex and more deeply engraved in Occidental culture than thematic studies on the subject are able to illustrate. It needs a thorough awareness of the cultural roots of the theme and the courage to consider philosophical anchors when ties with the specificity of legal discourse and actual tensions in modern culture are envisaged. The rethinking of legal themes in language and linguistic themes in law, as well as their inverse movements, appears to be richer than a simple mutuality of motives. That is the reason to rethink the "law-language" issue as a "law-language-law" theme. The theme is embedded in Occidental cultural thought from the Middle Ages up to today's globalization of law and language. In contrast to studies about "words" or "styles" and "grammars," or the unfolding of specific legal terminology such as "contract," "liability," or "legal capability," here the focus is on the multilevel phenomenon of "speech" in law-language relations.

\section{BEYOND SPEAKER AND HEARER}

The book invites us to rethink the contributions of jurists and legal theoreticians, political thinkers, linguists, and philosophers of language whose thought patterns were profiled by the "law-language-law" theme in Western culture. Hobbes appears to have naively implied a language model that endured throughout the ages of linguistic study and which bears the name "Speaker-Hearer Model" even today; von Savigny is studied in his critical texts on the Napoleonic Code and the conceptualization of his "people," of the "Volk"; thinkers of social commonness are studied for their views about legal and linguistic components of "alter" versus "alterity." Studies of UK and US authors on speech, on significs, on dualism or commonness such as Peirce, Austin, and Searle, together with German, French, Spanish, and Russian authors, deepen the field and provide more information about specific themes such as "semiotics," 
"structuralism," "dialogue philosophy," or the prodigious term "legal consciousness." They incorporate post-Hobbes variations of the "Speaker-Hearer Model," which profiles our Western culture and its thought patterns.

\section{THE FLAGSHIP'S WRECKAGE}

Rethinking the "law-language-law" theme brings our thoughts beyond that borderline model. It leads to the book's main thesis, which is formulated in the words of the book's subtitle, "The Flagship 'Speech'," and the title of this section, "The Flagship's Wreckage." That formulation includes various observations.

First, the rethinking we invite the reader to join leads to the insight that modern law is engaged in a forceful denial of the actual wreckage of speech. Resistance and denial seem necessary since alphabets, words, speech, texts, and related linguistic means of articulation are dangerously situated in the proximity of the global gap between two different language types: analog and digital language.

Second, the rethinking illustrates how law, if it is aware of this problem, tries to survive in the traditional way of thinking and acting through attempts of translation. The book analyses several attempts to parallel analog legal concepts (such as "subject," "speaker," "communication," "identity," and the like) with digital concepts, which are not yet declared positive law in actual legal language.

Third, our rethinking creates the insight that any such direct translation is impossible, for more than one reason: (a) our legal consciousness (a crucial concept since von Savigny and others) is untranslatable because of its deep identification with the basic components of our culture; (b) legal discourse embraces signs but not digits, since the latter do not embrace living speech; (c) living in a digital world requires different accents on the means/instruments of communication and changes our selves as creative factors in that process.

\section{THE SELF}

A comparison between semiotic or dialogue forms of communication on the one hand, and communication via apps, smartphones, post-texture talks registered in digital manners with digitally constructed devices on the other, will profile the problem called "wreckage." Are there translations at stake, are there transitions, or are we handed down to a world 
dependent on computerized conversion processes? The question focuses on changes in the human Self-a "self" that is by definition our changing energy - and thus transcends the classical speech situation, the Flagship of Western culture.

\section{SPEECH}

Since the terms "speech" and "flagship" are both efficacious metaphors for rethinking, this book is structured by two components, presented in a seemingly arbitrary order: chapters and intermezzos. The first present a rethinking of the "law-language-law" theme in accordance with problems of understanding and representation in concordance with a contemporary mind. They could function as if a handbook concerning the theme is available to be consulted. However, the rethinking of the theme, and its ties with change, continuity, and flux, requires at least an interruption of many of those handbook texts. The intermezzos act as a reminder of the necessity to respect a true rethinking. Each text, as traditionally summed up in handbooks, needs to be restated in other words, needs to be stimulated by means of lexical ambiguities that are provoked in the course of a representation. The rethinking should not avoid those complexities of change, which are characteristic of viewpoints and the revival of classical opinions in modern times. Each reformulation, the intermezzos suggest, is a form of rethinking within the context of the general theme. Their order suggests a view on the many perspectives of a rethinking mind, which is in all regards fascinated by the theme of the book. 